fine it. Irish universities are differentiated between tertiary (undergraduate) and fourth (postgraduate) level activity or institutions and UK universities between teaching-only and research universities. At the same time, a new network for Universities of Applied Sciences (http://www.uasnet.org) looks likely to flex its muscle.

\section{A New Shape?}

The details in each country vary but do represent a growing urgency to reform Europe's higher education institutions for competitiveness, while acknowledging that traditional universities can no longer meet all the geopolitical demands for research, development, and innovation. As part of this process, the European Commission is funding the development of a European "Carnegie Classification" with emphasis on broadening both horizontal and vertical differentiation.

European societies have hitherto perceived education as a social public good, available to everyone at little or no additional cost. While rankings are not the cause of the changes, they are fueling a reputational "arms race" and exploiting tensions between equity and excellence. Governments are using a combination of market mechanisms and competitive or performance- and output-based funding, with clear institutional mission descriptors or performance contracts. While the de jure binary may linger in some countries, the creation of a broadened and unified higher education system will further undermine its veracity. This will be a game of survival of the fittest.

\section{Performance-Based Funding of Universities: The Italian Experience \\ TOMMASO Agasisti}

Tommaso Agasisti is a junior researcher in the Department of Management, Economics, and Industrial Engineering at the Politecnico di Milano, Via G. Colombo, 40, 20133 Milan, Italy. E-mail: tommaso.agasisti@polimi.it.

$\mathrm{A}$ common international trend in higher education systems is the growing autonomy of universities, especially in financial matters. The role of central governments has become setting political priorities and financial incentives for stimulating autonomous universities to accept these priorities as objectives. It is important to design good models to allocate public resources among universities.

This trend is particularly relevant in Italy, where traditionally universities have held little autonomy and were subject to strong control by the central government. Starting in the I990s, numerous reforms have taken place in Italian higher education. The objectives of these reforms ranged from improving the financial autonomy of universities, giving them autonomy in the organization of teaching matters, and establishing procedures for higher education assessment. The most

The objectives of these reforms ranged from improving the financial autonomy of universities, giving them autonomy in the organization of teaching matters, and establishing procedures for higher education assessment.

important change involved the budget situation. A law approved in 1993 defined new principles for allocating resources from the central government to universities. The traditional procedure was based on line-item budgets: the central government allocated to each university budgets for each activity (e.g., teachers' wages and buying scientific facilities). This system had many problems since it did not encourage universities to form their own strategies about resource utilization. This mechanism was replaced by a lump-sum (block grant) budget, autonomously managed by each university. This reform forced universities to become more accountable. Now they have to manage resources without bounds and suggestions set by the Ministry of Education, Universities, and Research.

\section{The First Allocation Model}

After a period in which the allocation of public funds to universities was decided through a completely discretionary political process, in I997 a formula-based funding model was introduced. The formula had the explicit goal to equilibrate the resources among universities. The previous situation was characterized by allocations related not to indicators about universities' activities but rather to their political ability in contracting with the ministry, creating an imbalance across institutions.

The formula was adopted from 1997 to 2003 , but it was used for allocating only a part of the public budget: the main part of it was still distributed according to traditional procedures. The amount actually allocated through the formula was only I.5 percent in I997, but it increased to about Io percent in 2003.

This formula faced two main problems. It did not consider research activities, which are important for all the Italian institutions. Moreover, the weight attached to the number of students $(70 \%)$ excessively benefited large universities. Because of these problems, the government abandoned this formula and commissioned the National Evaluation Committee for a new one. The committee has rigorously worked on a perform- 
ance-based model for many years, trying several methodologies for measuring universities' activities and involving groups of experts at many universities. The committee's suggestions were seriously considered both by academic communities and by politicians.

\section{The New Model for Financing Universities}

In 2004, following the advice of the National Evaluation Committee, the government adopted a new formula. The main concept of this new formula represents the three groups of indicators: number of students (33\%), results of teaching activities $(33 \%)$, and the amount and results of research activities (33\%).

In the first indicator, the number of students is weighted according to different programs to reflect instructional costs (e.g., students in medicine are weighted more than students in economics). The second indicator, results of teaching activities, is measured by the number of credits obtained by students and by the number of graduates (weighted using "time for graduation").

The final indicator, results of research activities, is measured by comparing the number of teachers and researchers (also research assistants and PhD students) with the ability to obtain research-targeted financial resources from public and private companies and organizations and the rate of success in winning research funds from the ministry.

\section{POLICY IMPLICATIONS}

The new model seems to respond well to the challenges faced by Italian universities, even though critiques of the policy are ongoing. The indicators in the formula are coherent with national political strategies (increasing the number of students and graduates and also improving the quality of research through resources obtained by companies) and also address the multidimensional characteristics of universities' activities.

A few reflections can be drawn from the Italian experience, perhaps with international relevance, in terms of a possible agenda to be followed to develop a good performance-based system. First, the amount of resources allocated through the formula must be quite high, while in Italy it is definitely too low, because the formula is used for allocating only a part of the total public budget. In 2006 and 2007, about 99.5 percent of the budget was allocated according to traditional procedures and only 0.5 percent according to the formula. To improve the effects of incentives, the formula must be rapidly used for distributing at least Io to I5 percent of the public budget.

Second, the indicators for research must be as increasingly accurate as possible, including measures of quality. In Italy the indicators adopted are still quite rough (e.g., publication counts are not considered at all). The difficulty in adopting accurate measures is well known, but if one of the objectives remains to improve quantitatively and qualitatively the research relevance of Italian universities, adequate incentives must be established. The recent initiatives of the Italian
National Evaluation Committee for a qualitative assessment of research products (publications, patents, etc.) seem a feasible way for improving the data available.

Last but not least, the issue of differentiation must be considered. Giving the same incentives to all universities means accepting the uniformity of their activities. Based on the formula, each university should improve the quantity and the quality of its teaching and research to obtain a good score. Instead, internationally, the diversity of universities' offerings and their differentiation seem to be a positive trend, to improve efficiency and effectiveness of higher education performance as a whole-especially because the demand for higher education is increasingly differentiated. Perhaps, a possible option to face this challenge would be to separate research and teaching funds and to distribute them according to different formulas.

Examining these three issues can lead to a reconsideration of some important characteristics of the present performancebased formula in the Italian university system and can contribute to a wider international debate about the fundamental topic of better models for distributing public resources among universities.

\section{The University Entrance Exam Crisis in Iran}

\section{SHAHRZAD Kamyab}

Shahrzad Kamyab is an international education consultant. E-mail: shahrzadkamyabphd@yahoo.com.

Tn Iran, as in many other countries where a university entrance exam is the sole criterion for student selection, limited space and resources have restricted many talented and enthusiastic applicants seeking access to higher education. Consequently, the phenomenon of the university entrance exam has caused discontent and conflict.

In June each year, high school graduates in Iran take a stringent, centralized nationwide university entrance exam, called the Konkur, seeking a place in one of the public universities. The semiprivate Azad University holds a separate entrance exam. The competition is fierce, the exam content rigorous, and the seats at universities limited. In recent years, although the government has responded to demands for improved access and to a rapid increase in the rising number of applicants by enlarging the capacity of universities and creating Azad University, public universities are still only able to accept Io percent of all applicants. Last year I50,000 students among I. 4 million participants were admitted. Almost 60 percent of accepted applicants were women, as the participation of women in higher education has doubled over the last two 